\title{
A pilot programme to teach pharmacology using the international nonproprietary names in a pharmacy school in Spain
}

\author{
Conxita Mestres $^{1}$ iD, Marta Hernández Hernández ${ }^{1}$ iD, Nilhan Uzman², Màrius Duran ${ }^{1}$ iD, Raffaella Balocco ${ }^{3}$ (D) \\ ${ }^{1}$ School of Health Sciences Blanquerna, University Ramon Llull, Barcelona, Spain \\ 2 International Pharmaceutical Federation, The Hague, Netherlands \\ ${ }^{3}$ World Health Organization, Geneva, Switzerland
}

\section{Keywords}

Non-proprietary name

Pharmacology

Pharmacy

University

\section{Correspondence}

Conxita Mestres

School of Health Sciences Blanquerna

University Ramon Llull

Barcelona

Spain

concepciomm@blanquerna.url.edu

\begin{abstract}
Introduction: In pharmacology lectures, one of the major challenges faced by students is how students can remember an increasing list of a large number of drug names. Although university teachers use the international non-proprietary names (INNs) of drugs in their teaching practice, this is not enough to help students be competent in this area. Programme description: The School of Health Sciences Blanquerna, University Ramon Llull, was invited to join the World Health Organization (WHO) School of INN (SoINN) project as an expert consultant to represent the International Pharmaceutical Federation (FIP) Academic Institutional Membership (AIM). A pilot programme in utilising the INN in the pharmacology lecture in an undergraduate pharmacy programme was conducted. Evaluation: To assess how the students perceived this new topic, a short survey was conducted at the end of the term. Of the 32 students, $50 \%$ of them completed the survey. Most of them provided high value on the use of stems in their learning. Future plan: The current course was extended to other degrees of the pharmacy programme.
\end{abstract}

\begin{abstract}
Introduction
When teaching pharmacology, one of the main problems for students is how to make sense of and remember an increased list of a large number of drug names. While the university teachers use the international nonproprietary names (INNs) of drugs in their teaching practice, this is not enough to help students in achieving knowledge and being competent in this topic.
\end{abstract}

The international nonproprietary names (INN) nomenclature was developed by the World Health Organisation (WHO). The INN incorporates the use of stems which unify and give broad information about the pharmacologic group to which a drug belongs. This nomenclature helps students and professionals to be able to remember drug names easier. In the present paper, the authors described a pilot programme for the introduction of this new approach in pharmacology teaching in an undergraduate pharmacy programme.

The INN programme (WHO, 2017a) was established in 1951 by the WHO. The programme started in 1953, and its aim is to provide a common language for people all over the world to allow for the safe and effective use of medicines. The INN school was developed later with the objective of raising more awareness of the INN system, offering contributions to stakeholders and providing information and training for health professionals, students, academia, patients and members of the pharmaceutical industry.

At the 2018 European Association of Faculties of Pharmacy (EAFP) Conference and the $78^{\text {th }}$ International Pharmaceutical Federation (FIP) World Congress of Pharmacy and Pharmaceutical Sciences, the head of the INN programme delivered presentations about the 
INN programme. The authors gained knowledge about the WHO school of INN as well as Atomical Therapeutic Chemical - Defined Daily Dose (ATC-DDD) and the classification of medical products. The WHO Expert Group on INN developed a platform (School of International Non-proprietary Names, n.d.) with different courses for learning about INNs. The platform includes different modules such as 'Introduction to Drug Nomenclature and INN'; 'Learning Clinical Pharmacology (ATC classification, INN system)'; 'INN and Biological Active Substances'; 'Linguistic Aspects of INN' and 'Economics and Policy of INN Prescribing'. This group also developed a book, Learning clinical pharmacology, which describes the advantages of stems in education and the methodology for their implementation (WHO, 2017b).

The School of Health Sciences Blanquerna, University Ramon Llull, was invited to join the WHO School of INN (SoINN) project as an expert consultant to represent the FIP Academic Institutional Membership (AIM) which is a global network of pharmacy schools. All this was in accordance with FIP Development Goal (DG) 1: Academic capacity and DG 3: Quality assurance, which includes the following highlights: 1) Collaborate with academic leaders, professional organisations, regulatory bodies and the pharmaceutical industry to define regional and global needs for the pharmaceutical sciences; and 2) Build relationships with relevant stakeholders to best align the scientific content of academic courses with contemporary professional practice in pharmacy and pharmaceutical sciences (FIP, 2020).

In November 2018, some of the authors attended a two-day meeting in Madrid at the Agencia Española de Medicamentos Productos Sanitarios (AEMPS) with some of the members of the project. In this meeting, the group worked on the SoINN teaching modules in order to have them ready for the launching of the SolNN website in 2019. In April 2019, the team met again at the WHO headquarters in Geneva to follow the evolution of the project and agree on some collaboration proposals.

Drug names are being taught in the pre-and postgraduate programme of nursing, physiotherapy, nutrition and pharmacy in the School of Health Sciences. Therefore, it was thought that this programme was of paramount importance to be introduced in subjects such as pharmacology which is included in all the degrees. The authors agreed with FIP that a pilot project should be conducted in order to implement the use of INNs in the teaching of pharmacology in the school.

\section{Description of programme}

The implementation was done through a pilot programme (2020), undertaken in the subject of pharmacology. In the degree programme, pharmacology is divided between two semesters in the third year of the degree studies. Pharmacology I covers generic concepts and some pharmacologic groups, and Pharmacology II covers the rest of the groups. As some of the needed materials of the INN school were not available at the beginning of the first semester, the pilot study was done during the second term to be included in Pharmacology II (January - May 2020). Pharmacology II has six European credit transfer and accumulation systems (ECTS) and is structured in two weekly sessions of 90 minutes on theoretical concepts and one weekly session of work in small groups (20 students), also of 90 minutes duration, focused on practical aspects and clinical cases.

As described by the INN school (School of International Non-proprietary Names, n.d.), there are two main advantages to using stems in pharmacology education. These include the following: 1) within every pharmacological class, most pharmaceutical substances have a common stem, and 2) this stem is specific to a given pharmacological class.

\section{Pilot implementation}

On the first day of the term, the lecturer gave a brief presentation on the WHO School of International Nonproprietary Names, including the collaboration with FIP. The lecture covered the basic concepts relating to the stems and how they are applied, using different examples. The platform site of the school of INN was shown to the students, and they were encouraged to enrol in some of the modules. In the first session, the stems of biological drugs were not fully introduced due to the complexity of this class of substances. After this introduction, stems were included in all the lectures and activities that were performed during the semester in Pharmacology II.

The implementation was carried out using two strategies. The first strategy is through lectures, in which all the pharmacologic groups in the course were introduced with the ATC classification, then when explaining the different subgroups and drugs, the stem was included. If a drug had no stem, this was also indicated. This process would allow the student to see clearly the relation between the characteristics of the pharmacological group and the included drugs and the stem. This process was also conducted to emphasise this information so it would make it easier for students to remember the characteristics of the drugs included in each ATC. 
The second strategy is through the small group sessions, in which the team worked mainly on the resolution of clinical cases, where the student had a case of a patient with a list of medicines. Before the resolution of the case, the student was asked to find the stems of all the drugs included in the text and relate them to the pharmacological properties associated with those stems. For this purpose, the student had to access the documents of the WHO-INN school, where they could find the needed information: StemBook and Learning Clinical Pharmacology with the use of INNs and their stems (WHO, 2017b). As stated earlier, the terminology of stems for biological drugs presents more difficulties, and therefore, stems are introduced when these particular drugs are addressed. The authors think this approach is easier and more productive for students. This is specifically for Pharmacology II, where these drugs appear for the first time in the treatment of inflammatory bowel diseases.

\section{Evaluation}

In order to assess the students' knowledge, the students were given tests during the course (one at mid-term and one at the end). The tests included some questions relating to stems. Some examples of questions can be seen below.

The name of a drug that contains the stem "-gliptin" indicates that it is a:
a. Proton pump inhibitor
b. Azole antifungal
c. Antidiabetic inhibitor of DPP4

Drugs of the ACE Inhibitors group have the stem:
a. -sartan
b. -pril
c. -dipine

In terms of small group sessions, the students showed a good understanding of the programme of stems, as was detected in the resolution of the clinical cases.

\section{Course evaluation}

To assess how the students perceived this new approach, a short survey was conducted at the end of the semester. In order to encourage the students to answer the survey, the authors decided to keep the survey short and simple, but with the basic information that was thought to be useful for the full implementation of the programme during the next term. Of the 32 students, $50 \%$ of them completed the survey. Table I provides information on the results of the survey.

\section{Table I: Results of the survey}

\begin{tabular}{ll}
\hline Items & Mean (range) \\
\hline $\begin{array}{l}\text { 1. I consider that I have understood the } \\
\text { purpose of the use of the stems. }\end{array}$ & $3.4(2-4)$ \\
$\begin{array}{l}\text { 2. The use of stems helps to remember } \\
\text { and know to which pharmacological }\end{array}$ & $3.7(3-4)$ \\
group a drug belongs and other \\
properties that it may have.
\end{tabular}

In general, students responded to all items with more than the average of the sample. It is important to note that the students found the stems useful in the study of pharmacology, which is one of the main objectives of the stems. The students were generally eager to gain more knowledge about this topic, even though it was not an item with a higher score. The authors think that with respect to this item, the fact that this was the first time this concept was introduced is a contributing factor. Therefore, there will be a need to stress some aspects in order to make it more attractive for the students. Not many students made comments in the observations section; however, the majority expressed the thought that learning the stems was useful in their learning process. Table II provides information on some examples of the students' comments.

Table II: Some examples of students' comments

\begin{tabular}{l} 
Students' comments \\
\hline I think it's interesting to know the stems, because it makes it \\
easier to identify to which drug group the drug belongs, and that's \\
important, as there are a lot of drugs to know, and that helps. \\
It is true that thanks to the stem we know how to solve most of \\
the practical cases, because with the stem we can know the \\
pharmacological group. \\
The use of the stem in the lecture facilitates the learning of the \\
student and helps to locate more quickly the drug within the \\
pharmacological group to which it belongs. \\
I think it's a good way to classify among many others, to identify \\
drugs easier and more quickly. In general, it has made it easier for \\
me to learn about the different pharmacological groups, despite \\
some exceptions that may exist. \\
It seems to me a very useful tool, but the WHO web application it \\
is not very easy to follow. It would be better if it were more visual \\
(with images) and less text (not so much content, as far as the first \\
topics are concerned).
\end{tabular}




\section{Future plan}

Seeing that the student's learning process was improved as a result of this methodology, in the current course (2020-2021), the programme has been extended in two directions:

1. Introduction of the stems in Pharmacology I in the first semester (September-December 2020). There was a general presentation, and a whole session of the small group was devoted to doing exercises with stems, the inclusion of the teaching of pharmacology using stems in the two pharmacology subjects (I and II); 12 ECTS;

2. Introduction of a reduced version of the INN programme in the subject of pharmacology in the Degree of Human Nutrition and Dietetics (September-December 2020). This is in line with the FIP development goals (FIP, 2020), specifically DG 8: Working with others for interprofessional education and training.

The authors plan to do another revision of the entire programme in order to improve and develop some aspects, including the following:

1. Increase the practical activities, which include the use of stems;

2. Make the students more active and proficient in the learning of stems;

3. Make some of the basic modules of the INN school website compulsory to do; and

4. Increase the learning of stems in biological medicines.

The above is in addition to expanding the programme to the author degrees of school: Physiotherapy and Nursing.

\section{References}

International Pharmaceutical Federation (FIP) (2020). FIP development goals. FIP. Available at: https://www.fip.org/fipdevelopment-goals

School of International Non-proprietary Names (n.d.). School of international nonproprietary names. Available at: https://extranet.who.int/soinn/

World Health Organization (WHO) (2017a). Guidance on INN. World Health Organization health product and policy standards. Available at: https://www.who.int/teams/health-product-andpolicy-standards/inn/guidance-on-inn

World Health Organization (2017b). Learning clinical pharmacology with the use of INNs and their stems. World Health Organization. Available at: https://www.who.int/publications/i/item/who-emp-rht-tsn2018-02 